Association for Information Systems

AIS Electronic Library (AISeL)

Solopreneur Digital Ecosystems: Genesis, Lineage and Preliminary Categorization

Gabriele Piccoli

Biagio Palese

Joaquin Rodriguez

Follow this and additional works at: https://aisel.aisnet.org/bled2021

This material is brought to you by the BLED Proceedings at AIS Electronic Library (AISeL). It has been accepted for inclusion in BLED 2021 Proceedings by an authorized administrator of AIS Electronic Library (AISeL). For more information, please contact elibrary@aisnet.org. 


\title{
SOLOPRENEUR DigITAL ECOSYSTEMS: Genesis, Lineage and Preliminary CATEGORIZATION
}

\author{
Gabriele Piccoli, ${ }^{1}$ Biagio Palese ${ }^{2} \&$ \\ JOAQUIN RODRIGUEZ ${ }^{3}$ \\ ${ }^{1}$ Louisiana State University and University of Pavia, Business Education Complex, \\ Baton Rouge, Los Angeles 70803, United States of America; e-mail: \\ gpiccoli@cct.lsu.edu \\ ${ }^{2}$ Northern Illinois University, College of Business, DeKalb, Illinois 60115, United \\ States of America; e-mail: bpalese@niu.edu \\ ${ }^{3}$ Grenoble Ecole de Management, 12 rue Pierre Sémard, 38000 Grenoble, France; \\ e-mail: joaquin.rodriguez@grenoble-em.com
}

Abstract This paper traces the genesis and lineage of solopreneur digital ecosystems. These ecosystems, fostered by a digital environment that is infrastructural, combinatorial and servitized, are enabling the rise to prominence of the solopreneur. We theorize solopreneur digital ecosystems as the latest incarnation of systems beyond firm control, with digital platforms and digital marketplaces as their principal enablers. In an effort to compare them from the perspective of the solopreneur, we categorize solopreneur digital ecosystems on three dimensions: algorithmic control, commoditization, and lock-in. Our work contributes a framework that solopreneurs can use to identify ecosystems in which they can optimally invest their talents and scarce resources. We discuss the findings of this mapping and draw implications for research and practice.

Keywords:
digital
ecosystems,
solopreneur,
digita
resources,
creato
economy,
gig
economy

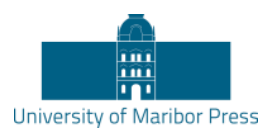

DOI https://doi.org/10.18690/978-961-286-485-9.18 ISBN 978-961-286-485-9 


\section{Introduction}

The prediction that "by reducing the costs of coordination, information technology will lead to an overall shift toward proportionately more use of markets-rather than hierarchies-to coordinate economic activity" (Malone et al 1987 p. 484) has proven true. What the prediction did not foreshadow, however, was that such markets would also be digital. As software continues to "eat the world" (Andreessen 2011), digital ecosystems have dramatically impacted business strategies and society more generally. One such impact is on individual's revenue generating activities and the growing opportunity to unbundle work from employment. As automation and machine learning advancements threaten a larger swath of traditional jobs (Manyika et al 2017), there is an unprecedented opportunity for human talent to be unleashed in digital ecosystems that enable demand and offer matching at a never-before-seen scale (Jin 2020).

According to the Oxford Dictionary, a solopreneur is »a person who sets up and runs a business on their own «. Solopreneurs, of course, are not a novelty of the digital age. But interest in solopreneurship has grown noticeably in the last two decades ${ }^{1}$ due to the rise of what we call solopreneur digital ecosystems (SDE). SDEs promise to simplify access to (self-)employment, particularly in disadvantaged or marginalized communities, by providing digital tools enabling solopreneurs to organize their work and overcome some of the barriers to employment they usually face (Dillahunt and Malone 2015). However, selection of a SDE is a critical early decision by solopreneurs seeking to maximize the return on their invested time and talents. This article takes the solopreneur perspective, investigating how digital enablers of different SDEs affect solopreneurs' strategic options. It contributes to a cohesive research agenda centered on SDE by providing an early categorization of their digital enablers and a framework to evaluate competing SDE. It also draws implications for research and practice based on the categorization of the ecosystems.

\footnotetext{
${ }^{1}$ The term did not appear until 1996, according to the Google Books ngram viewer, and grew more than 63-fold between its advent and 2019.
} 


\section{Theoretical foundations}

Before the advent of the Internet, organizational information systems were fully controlled by the firm that built, purchased or commissioned them to an outsourcer to operate on the firm's behalf. But the internet and the services built on top of it ushered in an era of systems beyond firm control. Systems beyond firm control are information systems neither designed nor commissioned by a firm that the organization must use to compete (Palese and Piccoli 2018). They are socio-technical arrangements that enable transactions and value exchanges. Online review systems, a prototypical example, have transformed how travelers search and share information. Their features and functionalities are not designed or controlled by travel companies, yet hoteliers, restaurateurs, and other travel operators cannot ignore dominant ones (e.g., TripAdvisor, Booking).

Systems beyond firm control are ecosystems: groups of interacting and interdependent entities and their environments. SDEs are a special kind of ecosystem in which the bulk of participants are solopreneurs serving end-consumers in an infrastructural, combinatorial and servitized environment that provides digital enablers (Piccoli et al 2020). Those digital enablers are digital platforms and digital marketplaces that allow the solopreneurs to organize and commercialize their work without formally joining a company in a traditional employment working arrangement. Digital enablers are the novel instruments solopreneurs use to create their products/services and/or the organizational processes to manage and run a business operation independently.

The definition of SDE advanced here is broad enough to encompass gig economy workers (e.g., Uber), social media influencers (e.g., Instagram) and digital creators (e.g., Twitch). It is in line with recent research that identifies "platform ecosystems" as "semi-regulated marketplaces that foster entrepreneurial action under the coordination and direction of the platform sponsor, or as multisided markets enabling transactions among distinct groups of users" (Jacobides et al 2018 p. 2258).

To categorize the variety of SDE, it is important to recognize the characteristics of the digital enablers that make them possible. To the best of our knowledge, the literature lacks such categorization, which makes it difficult to evaluate the inevitable trade-offs between competing SDEs and offer reliable guidance for maximizing 
cospecialized investments in competing ecosystems. We introduce and define the major categories of digital enablers that shape modern SDE.

\subsection{Digital Marketplaces}

Digital marketplaces are the digital spaces in which buyers and sellers "exchange product information, coordinate, and transact" (Pavlou and Gefen 2004 p. 40). They exercise control over the products and services listed by sellers (Eaton et al 2015). Thus, digital marketplaces differentiate themselves by exercising control over the type, characteristics, number, and quality of products and services offered by sellers. They enable trust between buyers and sellers by guaranteeing levels of customer protection (e.g., refunds), reliable payment transfers (e.g., escrow services), and mechanisms to ensure that transactions are based on accurate and reliable information (e.g., ratings) (Pavlou and Gefen 2004. Finally, they facilitate discovery of products and services by customers ( $\mathrm{Li}$ et al 2018). Digital marketplaces with a significant number of suppliers incur high search costs and seek to reduce costs by implementing tools that enable customers to easily find products and services of interest.

\subsection{Digital Platforms}

In line with recent literature, we define digital platforms as evolving sociotechnical systems with modular design architecture that expose digital resources module designers use to produce innovations (Constantinides et al 2018). We define digital resources as a specific class of digital objects (Faulkner and Runde 2019) that a) are modular; b) encapsulate objects of value, namely specific assets and/or capabilities; c) and are accessible by way of a programmatic bitstring interface (Piccoli et al 2020). By specifying a modular architecture and exposing digital resources, digital platforms enable the creation of new modules (i.e., complementors) that extend their functionality. More importantly, they offer combinatorial and servitized resources solopreneurs can leverage to build innovative products and services (i.e., vertical platforms) and devise new business models (i.e., horizontal platforms). Depending on their architecture, characteristics, and variety of digital resources exposed, digital platforms engender different levels of generativity (Zittrain 2006). For example, a highly generative platform like Roblox enables solopreneurs to create an infinite variety of games and applications for the Roblox "metaverse." On the other end of 
the spectrum (i.e., the extensibility of the platform is zero), the platform becomes a tool. For example, Substack provides a number of resources for solopreneurs in newsletter and podcasting spaces. These individuals can create products (e.g., a newsletter) and run businesses (e.g., manage mailing lists, collect payment) by configuring/using instruments made available by Substack. However, Substack does not expose interfaces that enable complementors to contribute new modules or enable solopreneurs to extend the functionality of existing modules.

\subsection{Integrated Platforms and Marketplaces}

While early research treated platforms and marketplaces as interchangeable constructs (Rochet and Tirole, 2003), more recent work has articulated the difference between the two (Benlian et al 2015). An increasing number of organizations purposefully integrate and simultaneously manage a digital platform and a digital marketplace (Ghazawneh and Henfridsson 2015). By doing so they concurrently control marketplace and platform functionalities. The integration of the two yields unprecedented power through the simultaneous control of the products/services (via platform ownership) and distribution and monetization channel (via marketplace ownership). In this type of SDE, solopreneurs are required to abide by both a prespecified product or business architecture and marketplace governance rules enforced by the owner of digital enablers at the center of the ecosystem. Examples include ecosystems anchored by such firms as Amazon in retail, Spotify in podcasting, or Deliveroo in food delivery. They represent the latest examples in the evolution of systems beyond firm control.

\section{Solopreneur digital ecosystems as algorithmic economies}

Solopreneur digital ecosystems are characterized by resources made available by digital platform and digital marketplace owners. Those resources enable transactions between solopreneurs and consumers as well as creation of solopreneurs' products or services. Thus, SDEs become "algorithmic economies" in which decision-making coordination and control functions are embedded in the ecosystem's digital enablers' algorithms (Möhlmann et al 2020). Consider, for example, product visibility in physical retail. It is characterized by limited shelf space, managed through ad hoc contractual agreements, and has stable underlying performance drivers. Conversely, digital shelves in a digital marketplace are theoretically unlimited, and product 
visibility is determined by evolving algorithms that operate in real time and are often proprietary and inscrutable. This distinctive characteristic of algorithmic economies represents an added layer of complexity solopreneurs need to manage when joining a digital ecosystem.

\section{$4 \quad$ Preliminary classification dimensions}

Keeping with our focus on investigating how the digital enablers of different SDEs affect solopreneurs' strategic options, we advance a preliminary categorization of SDEs based on analysis of the primary digital enablers of each ecosystem. These enablers expose digital, IT and complementary resources (Piccoli and Ives 2005, Piccoli et al 2020) supporting solopreneurs in the development and/or commercialization of their innovations (i.e., products and services). Solopreneurs in turn orchestrate a purposefully arranged set of resources in pursuit of their goals. Such goals are typically commercial, measured in revenue and profits, but can also be personal (e.g., self-actualization, validation). The focus on solopreneurs as the primary beneficiaries of our work requires a categorization that, while concentrating on digital enablers as the unit of analysis, is designed to be practical for solopreneurs deciding in which ecosystems to optimally invest their talents and scarce resources. Specifically, we adopt the following three dimensions:

- Algorithmic control. This dimension captures the automatic enforcement of control mechanisms through algorithms implemented in software programs (Möhlmann et al 2020). It determines the degrees of freedom solopreneurs can exert as they operate within the ecosystem. It includes control over the product or service specifications (e.g., Uber's eligibility for Uber Black as a rating above 4.85), control over the manner in which work is organized (e.g., Uber's expectation that riders accept a ride withing 15-30 seconds), and control over the solopreneur's relationships with customers and the visibility of their offerings (e.g., Uber's algorithmic matching of riders to drivers).

- Commoditization. Commoditization stems from the design features adopted by digital enablers. While the fungibility of what the solopreneurs produce is an important consideration, with highly fungible solopreneur offerings being more substitutable, commoditization is a function of the resources that the enablers expose to solopreneurs and the functionalities 
available to users. Consider the example of Instacart, the grocery delivery marketplace, and Dumpling, a competing digital platform designed to offer "everything you need to start, run, and grow your own personal shopping business." Instacart personal shoppers are entirely fungible, since there are no features in Instacart to request a specific shopper and all interactions between the shopper and the customer are managed within the app. Conversely, Dumpling's design is geared toward enabling the shopper to develop and maintain a base of recurring customers who trust her. Over time, personal shoppers on Dumpling become non-fungible to their loyal customers.

- Creator lock-in. Lock-in is a function of switching costs, defined as the current value of all the tangible and intangible co-specialized investments the solopreneur has made in the ecosystem (Piccoli and Ives 2005). The higher the switching costs, the more difficult it is for solopreneurs to continue operating when migrating to a competing ecosystem. Uber drivers lose their driving history and reputation score if they migrate to a competitor (e.g., Lyft). Since history and reputation are critical input to the matching algorithm, or the ability to offer premium services (e.g., Uber Black), lockin is substantial. Conversely, while a writer migrating from Substack needs to learn how to operate her newsletter in the competing ecosystem (e.g., Revue), Substack writers own their mailing list and payment relationship with subscribers (i.e., switching costs are relatively low). However, "even when switching costs appear low, they can be critical for strategy" (Shapiro and Varian 1999, p. 108), with the critical element being "not the absolute magnitude of the cost of switching, but its size relative to the value received from the [platform resources]" (Piccoli and Ives, 2005 p. 762).

\section{$5 \quad$ Data and Results}

While the three dimensions are clearly related, they capture different aspects of the decision-making space solopreneurs must investigate when deciding which ecosystem to select. We screened 200 digital enablers, evaluating the Gross Merchandise Value (GMV), number of active solopreneurs and users in their ecosystems. ${ }^{2}$ We selected the top 10 by GMV, by number of users and number of

\footnotetext{
${ }^{2}$ We used the list on Sidehustlestack (https://sidehustlestack.co/) as the starting point of our selection.
} 
solopreneurs. We classified the resulting 30 distinct $\mathrm{SDEs}^{3}$ by type of primary digital enabler (i.e., digital platforms, marketplaces and integrated platforms and marketplaces) and rated them on a scale from 1 (lowest) to 5 (highest) for algorithmic control, commoditization and lock-in. ${ }^{4}$ The top 30 solopreneur digital ecosystems are anchored by 4 digital platforms, 14 digital marketplaces and 12 integrated platforms and marketplaces. We detected significant variability across the three dimensions of algorithmic control, commoditization and lock-in (Table ).

Table 1: Descriptive Statistics by Digital Enabler category

\begin{tabular}{|l|c|c|c|}
\hline & $\begin{array}{c}\text { Digital } \\
\text { Platforms }\end{array}$ & Marketplaces & $\begin{array}{c}\text { Integrated Platforms and } \\
\text { Marketplaces }\end{array}$ \\
\hline Number & 4 & 14 & 12 \\
\hline $\begin{array}{l}\text { Algorithmic control } \\
\text { (mean) }\end{array}$ & 2.25 & 2.64 & 2.83 \\
\hline $\begin{array}{l}\text { Algorithmic control } \\
\text { (sd) }\end{array}$ & 0.50 & 1.08 & 0.84 \\
\hline $\begin{array}{l}\text { Commoditization } \\
\text { (mean) }\end{array}$ & 2.25 & 3.29 & 3.17 \\
\hline $\begin{array}{l}\text { Commoditization } \\
\text { (sd) }\end{array}$ & 0.50 & 0.83 & 1.19 \\
\hline Lock-in(mean) & 2.75 & 3.14 & 3.33 \\
\hline Lock-in(sd) & 0.50 & 0.95 & 1.07 \\
\hline
\end{tabular}

These results indicate that the characteristics of solopreneur digital ecosystems heavily depend on the design choices of their primary digital enablers rather than on uncontrollable or inherent characteristics of the ecosystems. In other words, the solopreneurs compete within an algorithmic economy they can perhaps influence, but certainly cannot control (i.e., a system beyond firm control). Instead control of the system rests with the firms that design, manage and own the primary digital enablers. Our results also show significant differences across the three types of digital enablers, with marketplaces and integrated platforms and marketplaces showing similar patterns, while platforms diverge. This preliminary observation may indicate some mimetic tendencies by competing digital enablers. Alternatively, it may

\footnotetext{
${ }^{3}$ If a platform was among the top 10 in multiple lists, we included it only once. On each list we continued selection until we classified 10 digital enablers of solopreneur digital ecosystems (e.g., Uber was top 10 in all 3 dimensions, but we included it only in the top 10 by GMV).

${ }^{4}$ Following Krippendorff (2018) we provided a classification procedure to two independent coders (available upon request to the authors) and computed inter-rater reliability. We recorded a kappa value of 0.93 . In the second stage, a third coder reviewed only the SDEs without full agreement. Those SDEs were discussed among the coders in a consolidation meeting that lead to full agreement.
} 
be that the type of digital enabler constrains, at least in part, its owner's design choices (see discussion).

Table 2: GMV, users and solopreneurs statistics by ecosystems type

\begin{tabular}{|l|r|r|r|}
\hline Ecosystem type & $\begin{array}{c}\text { Digital } \\
\text { Platforms }\end{array}$ & $\begin{array}{c}\text { Digital } \\
\text { Marketplaces }\end{array}$ & $\begin{array}{c}\text { Integrated Platforms } \\
\text { and Marketplaces }\end{array}$ \\
\hline GMV (mean) & $456,750,000$ & $507,092,857$ & $1,562,829,667$ \\
\hline Users (mean) & $175,750,000$ & $98,838,182$ & $24,740,000$ \\
\hline Solopreneurs (mean) & 366,667 & $1,780,000$ & $1,533,917$ \\
\hline
\end{tabular}

SDEs anchored by firms that integrate a platform and a marketplace in our sample have the highest average GMV (Table), about three times higher than an SDE anchored by either a digital marketplace or a digital platform. This result shows the power of integrating the two enablers, likely stemming from their ability to control resources underpinning solopreneurs' products/services and their transactions with consumers. It appears that the most successful firms that integrate both a platform and a marketplace enable superior value propositions and successfully aggregate customers demand, resulting in higher GMV.

Marketplaces, be it as a standalone enabler or when integrated with a platform, attract, on average, a larger number of solopreneurs, with digital platforms only reaching a fifth of the other two types of digital enablers. This result may depend on the draw and incentives SDEs anchored by a digital marketplace create for solopreneurs. As marketplaces provide direct access to customers, it is a simple strategic decision to join - but simple may not imply advantageous (see discussion).

The above argument leads to the expectation that marketplaces also dominate in number of users. The opposite is true in our sample, which suggests marketplaces only draw a subset of consumers in most markets. ${ }^{5}$ Conversely, lacking a marketplace, digital platforms focus on providing tools to reach and serve all consumers in an addressable market. When successful, digital platforms empower solopreneurs to serve customers both directly and across marketplaces - resulting in successful digital platforms attracting twice as many customers as the average marketplace and seven times as much as the average integrated platform and

\footnotetext{
${ }^{5}$ Amazon, widely seen as a monopolist in the US, only controls about $35 \%$ of ecommerce transactions by value and only $6 \%$ of all retail.
} 
marketplace. Charting distributions of SDEs across the three dimensions shows how most combinations are completely absent (87.2\%), with 21 of the 30 observations concentrated in only 7 combinations. While the low number of ecosystems codified in this preliminary study is likely responsible for these results, the observation points to some converge toward the dominant designs. Moreover, stricter configurations (e.g., 4, 5, 5) appear viable only when the digital enabler encompasses a marketplace.

\section{Discussion and Conclusions}

Taken together, our results suggest that while the draw of marketplaces may be inescapable, solopreneurs must be weary of their power. The limited number of digital platforms we categorized, compared to the other two types of digital enablers, suggests that control of a marketplace contributes to growth in terms of GMV and the ability to attract solopreneurs. However, digital platforms dominate in the number of users in the ecosystem. In other words, controlling a marketplace helps firms that own the primary digital enabler of a solopreneur digital ecosystem to also serve as the catalyst for supply. We speculate this feature attracts solopreneurs because it simplifies their "route to market." However, such simplification comes at a cost, making the solopreneurs more dependent on the firm that owns critical marketplace resources since they mediate the solopreneur's ability to develop a digital relationship with customers.

The above result is corroborated by the average score of each digital enabler type on algorithmic control, commoditization and lock-in. Digital enablers that include a marketplace are fairly consistent, with scores that exceed digital platforms by about $30 \%$. We ascribe this result to the control marketplaces exert over solopreneurs' commercialization practices. Moreover, there appears to be a positive correlation between algorithmic control and commoditization, which hints at the need to standardize the signals and variables used for representing solopreneurs' creations. In other words, there may be an implicit commoditization pressure of solopreneurs' creations, even when not purposedly designed by digital enabler owners who, in search of efficiency through algorithmic control, seek to enforce standards in categorization and evaluation of offers. Solopreneurs in these digital ecosystems compete for visibility with only a limited understanding of the algorithm's inner workings and the casual paths that govern the relationship between actions and results. The algorithms can rapidly, continuously, and comprehensively evaluate 
solopreneurs' products and services, resulting in an economy that is hypercompetitive and commoditizing toward suppliers (Möhlmann et al 2020).

The above pressures are not present in digital platforms, which lack marketplace control. The search for algorithmic efficiency is focused on work processes that enable the solopreneur and result in a low commoditization score. Digital platforms may inherently spur differentiation and innovation in product/service and business model/operations. We are convinced that design choices by the digital enabler owners are critical; however, preliminary results point to structural differences between the types of enablers.

We summarize our analysis in the following $2 \times 2$ matrix, mapping the depth and breadth of commercialization services and of product and/or operations support digital enablers provide (Figure).

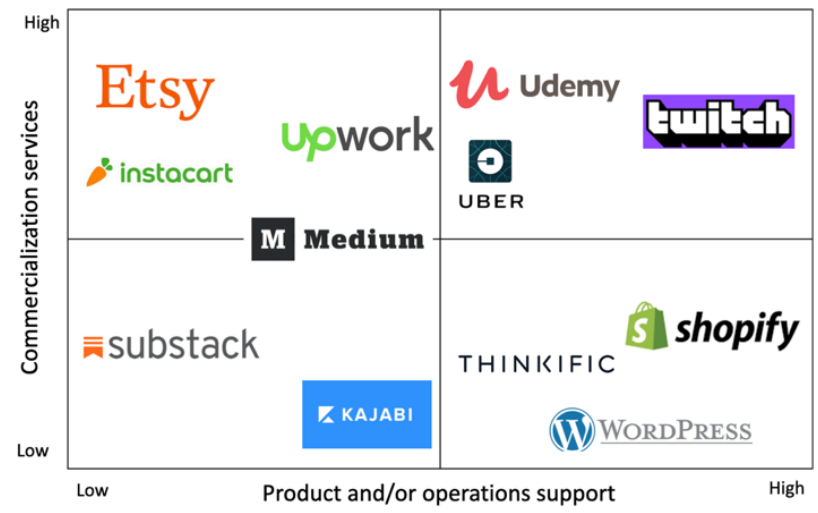

Figure 2: Dimensions of Digital Enablement in Solopreneur Digital Ecosystems Source: authors

The matrix captures the type of analysis our work offers to solopreneurs seeking to strategically invest their talents and scarce resources. On the one hand, deeper support generally speeds up product/service creation, market access and transaction completion. But when leveraging a wider array of digital resources offered by the enablers, the solopreneur must carefully analyze the design to evaluate the resulting degree of algorithmic control, commoditization and lock-in. As an illustration, we mapped the 10 most representative SDE in our sample. We hope that, despite its 
limitations, our preliminary work will inspire future research focused on helping the emerging middle class of solopreneurs (Jin 2020) to take advantage of the increasing opportunities to unbundle work from employment in solopreneur digital ecosystems.

\section{References}

Andreessen, M. (2011). "Why Software Is Eating the World," Wall Street Journal. (https://www.wsj.com/articles/SB10001424053111903480904576512250915629460, accessed July 15, 2018).

Benlian, A., Hilkert, D., \& Hess, T. (2015). How open is this Platform? The Meaning and Measurement of Platform Openness from the Complementers' Perspective. Journal of Information Technology, 30(3), 209-228. https://doi.org/10.1057/jit.2015.6

Constantinides, P., Henfridsson, O., and Parker, G. G. (2018). Platforms and Infrastructures in the Digital Age, Information Systems Research (29:2), pp. 381-400. (https://doi.org/10.1287/isre.2018.0794).

Dillahunt, T. R., and Malone, A. R. 2015. "The Promise of the Sharing Economy among Disadvantaged Communities," in Proceedings of the 33rd Annual ACM Conference on Human Factors in Computing Systems, CHI '15, New York, NY, USA: Association for Computing Machinery, April 18, pp. 2285- 2294.

Eaton, B., Elaluf-Calderwood, S., and Sorensen, C. (2015). "Distributed Tuning of Boundary Resources: The Case of Apple's IOS Service System,” MIS Quarterly (39:1), 217+

Faulkner, P., and Runde, J. (2019). Theorizing the Digital Object, MIS Quarterly (43:4).

Jacobides, M. G., Cennamo, C., and Gawer, A. (2018). "Towards a Theory of Ecosystems," Strategic Management Journal (39:8), pp. 2255-2276. (https://doi.org/10.1002/smj.2904).

Jin, L. (2020) The Creator Economy Needs a Middle Class. Harvard Business Review.

Jin, L. (2020) Unbundling Work from Employment. Substack. Available at: https://li.substack.com/p/unbundling-work-from-employment

Li, L., Chen, J., \& Raghunathan, S. (2018). Recommender system rethink: Implications for an electronic marketplace with competing manufacturers. Information Systems Research, 29(4), 1003-1023.

Malone, T., Yates, J., and Benjamin, R. (1987). Electronic markets and electronic hierarchies. Communications of the ACM 30 (6), 484-497

Manyika, J., Chui, M., Miremadi, M., Bughin, J., George, K., Willmott, P., Dewhurst, M. (2017). A future that works: Automation, employment, and productivity. Mckinsey. Available at: https://www.mckinsey.com/ /media/McKinsey/Featured\%20Insights/Digital\%20Disrupti on/Harnessing $\% 20$ automation $\% 20$ for $\% 20 \mathrm{a} \% 20$ future $\% 20$ that $\% 20$ works/MGI-A-futurethat-works_Full-report.pdf

Möhlmann, M., Zalmanson, L., Henfridsson, O., \& Gregory, R. W. (2020). Algorithmic management of work on online labor platforms: when matching meets control. MIS Quarterly: Management Information Systems, 1-54.

Palese, B., and Piccoli, G. (2018). Effective Use of Systems Beyond the Firm's Control: The Case of Online Review Systems, In Proceedings of the 39th International Conference of Information Systems, San Francisco, USA

Pavlou, P. and Gefen, D. (2004.) Building effective online marketplaces with institution-based trust

Information Systems Research, 15 (1) (2004), pp. 35-62

Piccoli, G., and Ives, B. (2005). II-Dependent Strategic Initiatives and Sustained Competitive Advantage: A Review and Synthesis of the Literature, MIS Quarterly (29:4), pp. 747-776. 
Piccoli, G., Rodriguez, J, and Grover, V. (2020) Strategic Initiatives and Digital Resources: Construct Definition and Future Research Directions. , In Proceedings of the 41st International Conference of Information Systems, India

Rodriguez, Joaquin, and Gabriele Piccoli. "Competing within Aggregators: Competitive Moves in the Deliveroo Online Delivery Platform." (2020).

Rochet JC, Tirole J (2003) Platform competition in two-sided markets. Journal of the European Economic Association 1(4):990-1029

Shapiro, C., and Varian, H. R. (1999). The art of standards wars. California management review, 41(2), 8-32.

Tapscott, D. (2001). Rethinking strategy in a networked world [or why Michael Porter is wrong about the internet]. strategy and business, 34-41.

Zittrain, J. (2006). The Generative Internet. Harvard Law Review, Vol. 119, p. 1974, Available at SSRN: https:/ / ssrn.com/abstract $=847124$ 
